\title{
Reducing the noise pollution level along main roads in Sibiu, Romania by optimizing the traffic flow
}

\author{
Cristian Deac*, Valentin Petrescu, and Alina Gligor \\ ${ }^{1}$ Lucian Blaga University of Sibiu, Romania, Department of Industrial Engineering and Management, \\ Emil Cioran str., 4, Sibiu, Romania
}

\begin{abstract}
Noise pollution is one of the most important negative effects of road traffic, especially in cities. The current paper presents an attempt to reduce the noise level created by the road traffic along some main roads in the city of Sibiu, Romania by suggesting ways to optimize the traffic flow. The number of cars and the resulting noise levels were recorded in a key area of Sibiu. The noise levels were compared to standards and to measurements taken in areas with less traffic. Then, they were fed, together with road geometry data, into a specialized simulation software that allowed the computer-aided reproduction of the traffic flow, but also the modifying of conditions such as the road geometry to achieve, coupled with a multicriterial analysis, an optimization of the pedestrian and road traffic flow in view of a reduced noise pollution.
\end{abstract}

\section{Introduction}

The rapid increase of the world population in the last few decades has led to an increased crowdedness especially in the larger cities, which generally translates into larger delays for the travel to, within or from those cities, but also into more pollution, both in terms of noxious gaseous emissions and in terms of noise [1].

The city of Sibiu is located in central Romania and has a stable population of around 150000 inhabitants. It must be added however, that the city is an important industrial and commercial centre and also has a rich culture and history, so there is also a significant temporary population - tourists, businessmen, workers etc. All this contributes to a significant pressure on the road structure of the city, which, despite sustained efforts over the years, continues to lead to difficulties in driving through the city, but also leads to an increased pollution.

In the current paper, the authors analyzed the traffic conditions in a key area from the central part of Sibiu, Romania and, with the help of specialized software instruments, offer some solutions for the decrease of the road traffic levels and also, at the same time, for the decrease of the noise pollution level.

\footnotetext{
* Corresponding author: cristian.deac@ulbsibiu.ro
} 


\section{The analyzed area, means and method}

For the current paper, the authors have focused on the area around the Unirii square in the centre of Sibiu, which represents an important crossroads area, where the north-south road traffic intersects with the east-west road traffic through the city (Figure. 1).

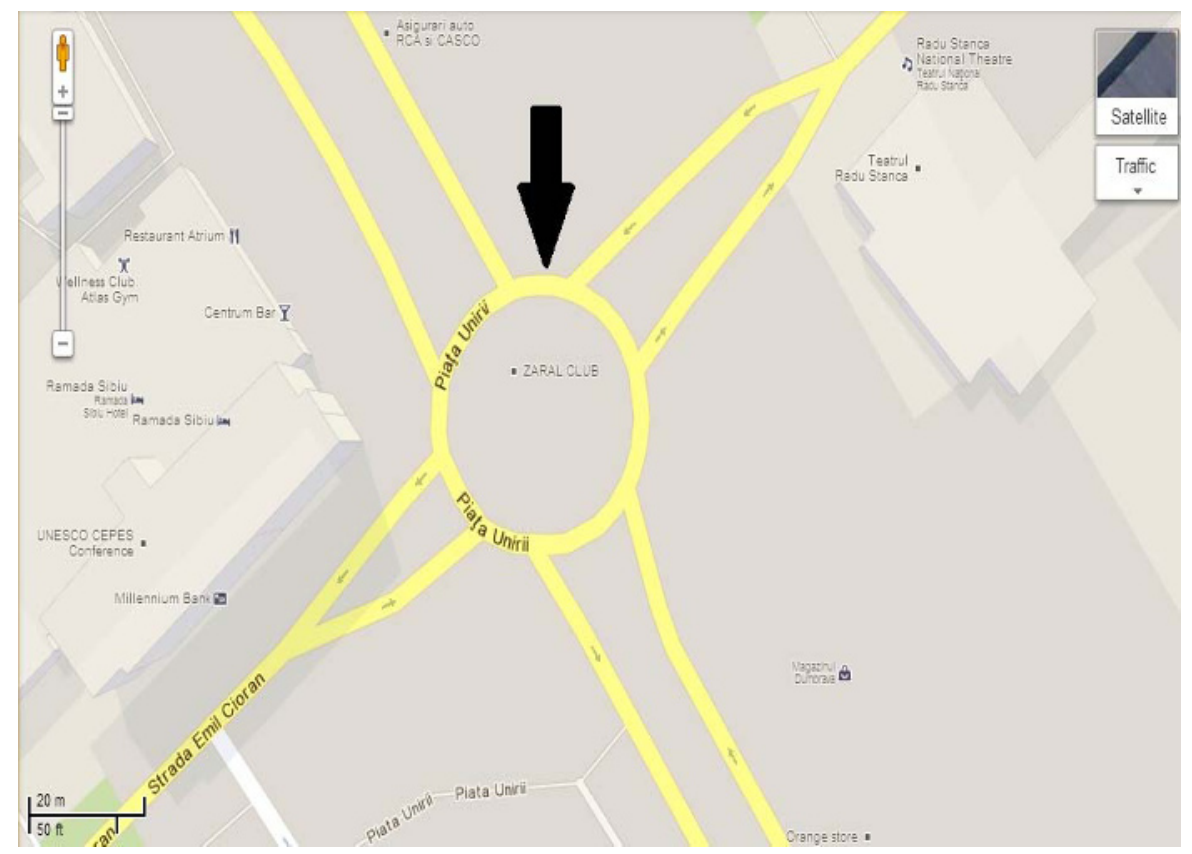

Fig. 1. The Unirii square and crossroads in central Sibiu, targeted by the present study.

In this area, both the road traffic and the pedestrian traffic are very busy, for following reasons:

- It is located close to the city's historical centre;

- It is an area of economical and administrative interest (in or near to it there are residential areas, but also important institutions such as banks, hotels, shopping centres, the local Police headquarters, a hospital etc.)

- The area is crossed or bordered by a series of main roads that connect the various neighborhoods in the city but also funnel the traffic towards the exits from the city and towards the surrounding cities;

Even if the geometry of the crossroads seems to be well organized, during peak hours their traffic capacity is visibly surpassed and there is an excessive sound level pressure. Especially in the morning there result long waiting queues on some directions.

The intended analysis seeks to determine the precise traffic and noise pollution conditions and to find the optimal solutions for reducing or possibly eliminating the problems.

The main activities that were carried out for this study included:

- $\quad$ analysis of the studied area

- collection of data regarding the traffic conditions

- simultaneously, collection of data regarding the noise pollution conditions

- comparison of the noise pollution data with the relevant national standards

- modelling of the crossroads area in a specialized software and simulation of the traffic conditions

- determining optimization solutions for the traffic and for the pollution. 
The data regarding traffic conditions can be collected using one of the following methods [2]:

- manual collection using a team of human observers

- analysis of video recordings

- collection using specialized equipment (sensors, GPS etc.)

When assessing the collected data, there need to be taken into account also factors such as the meteorological conditions, the traffic intensity and the traffic's complexity. Also, it is important to select appropriate time periods for the counting.[2,3]

For the current study, the data on the number of vehicles passing through the crossroads from various directions and heading to various directions was collected by means of video recordings, on several days, using time periods of 15 minutes each. After that, the recordings were reviewed and the vehicles were counted manually.

Beneath the actual car counting on each individual lane, several other elements were recorded, in order to facilitate the subsequent computer-aided modelling of the traffic in the crossroads area:

- the crossroads' geometry and equipment

- the traffic light cycles and the corresponding durations of each colour

- the pedestrian traffic

- the length of waiting queues

- frequency of the public transportation means etc.

Given that the traffic flow through the crossroads contained different types of vehicles (small cars, motorcycles, trucks, buses etc.), the authors have applied the coefficients indicated in the standard SR 7348-2001 [4] for obtaining numbers of so-called equivalent vehicles using the formula:

$$
\mathrm{N}_{\text {equiv }}=\mathrm{N}_{1} \mathrm{c}_{1}+\mathrm{N}_{2} \mathrm{c}_{2}+\ldots+\mathrm{N}_{\mathrm{i}} \mathrm{c}_{\mathrm{i}}
$$

where:

$\mathrm{N}_{\text {equiv }}$ - number of equivalent vehicles for the considered traffic flow and time period;

$\mathrm{N}_{1}, \mathrm{~N}_{2}, \ldots, \mathrm{N}_{\mathrm{i}}$ - number of vehicles of a certain type in the flow;

$\mathrm{c}_{1}, \mathrm{c}_{2}, \ldots, \mathrm{c}_{\mathrm{i}}-$ correction coefficients corresponding to each type of vehicle. For example, for cars, $\mathrm{c}=1$, for motorcycles $\mathrm{c}=0.5$ and for buses $\mathrm{c}=3.5$.

Since there have been counted only very few motorcycles and also very few trucks (most of the heavy traffic uses the ring road around Sibiu without entering it), these vehicle categories have been neglected in the actual vehicle count.

Also, in parallel there has been determined the noise level in the crossroads for the same time ranges, thus allowing a correlation of the results.

The noise level can be determined for individual vehicles (useful for assessing the noise produced by each category of vehicles) or for the entire road flow.

The main noise sources in the road traffic are $[5,6]$ :

- noises emitted by the car engines;

- noises emitted by the contact between wheels and roads;

- noises made by the air currents when interacting with the vehicles;

- other sources (brakes, door slamming, loading/unloading etc.);

The noise levels were measured using a sound level meter model 2100 made by Quest Technologies, from the endowment of the Faculty of Engineering of the "Lucian Blaga" University of Sibiu, Romania. In order to obtain a clear signal and to eliminate disturbance factors, the sound level meter was equipped with a band-pass filter.

The traffic data were then input into the specialized software package Synchro Studio 7. For this, the authors first modelled the geometry of the crossroads and then the traffic-related data were added. The main element determined using this traffic simulation was the so-called crossroads usage capacity. This was then used as base for a comparison with a proposed optimization solution. 
The optimization of the traffic in the analyzed crossroads was based on modifications to the crossroads' geometry, even if the existing geometry does not allow to carry out major changes.

The adopted optimization solution consisted in the adding of a supplemental lane on one direction (Unirii square, descending) where only right turns are allowed and also one supplemental lane each on two other roads (Unirii square, ascending and Corneliu Coposu Blvd.) where only left turns were allowed.

In the end, considerations were made regarding the noise level in the optimized solution.

\section{Results and discussion}

The data obtained after counting the vehicles passing through the crossroads coming from the Unirii square (descending branch), according to their type and direction in which they were heading, is presented in Table 1.

Table 1. Number of vehicles counted on the Unirii square (descending branch) according to their type and the direction in which they were heading.

\begin{tabular}{|l|c|c|c|c|c|c|c|c|c|c|c|c|c|c|c|}
\hline \multicolumn{2}{|c|}{ Type of vehicle } & \multicolumn{3}{|c|}{ Cars } & \multicolumn{3}{c|}{ Bus0es } & \multicolumn{3}{c|}{ Trucks } & \multicolumn{3}{c|}{ Vans } & \multicolumn{2}{c|}{$\begin{array}{c}\text { Motor- } \\
\text { cycles }\end{array}$} \\
\hline $\begin{array}{l}\text { Movement direction } \\
\text { Time range }\end{array}$ & $\leftarrow$ & $\uparrow$ & $\rightarrow$ & $\leftarrow$ & $\uparrow$ & $\rightarrow$ & $\leftarrow$ & $\uparrow$ & $\rightarrow$ & $\leftarrow$ & $\uparrow$ & $\rightarrow$ & $\leftarrow$ & $\uparrow$ & $\rightarrow$ \\
\hline $7: 30-7: 45$ & 80 & 231 & 35 & 4 & 3 & - & - & 3 & - & 6 & 28 & - & 2 & 1 & - \\
\hline $7: 45-8: 00$ & 119 & 447 & 44 & 3 & 3 & - & - & 4 & - & 4 & 21 & 1 & 2 & - & - \\
\hline $8: 00-8: 15$ & 48 & 219 & 28 & 3 & 3 & - & 1 & 3 & - & 3 & 16 & - & - & - & - \\
\hline $8: 15-8: 30$ & 34 & 156 & 21 & 3 & 3 & - & 2 & 1 & - & - & 18 & 2 & - & 1 & - \\
\hline
\end{tabular}

Since the data corresponding to all 4 branches of the crossroads would lead to a very large table, in Table 2 these data have been presented after applying the equivalation formula 1 for all vehicles except buses, which are indicated in a special row.

Table 2. Number of vehicles determined for all branches of the studied crossroads.

\begin{tabular}{|c|c|c|c|c|c|c|c|c|c|c|c|c|}
\hline Road & \multicolumn{3}{|c|}{$\begin{array}{c}1 \\
\text { Emil Cioran } \\
\text { str. }\end{array}$} & \multicolumn{3}{c|}{$\begin{array}{c}\text { 2 } \\
\text { Unirii square } \\
\text { (descending) }\end{array}$} & \multicolumn{3}{c|}{$\begin{array}{c}\text { 3 } \\
\text { Corneliu } \\
\text { Coposu Blvd. }\end{array}$} & \multicolumn{3}{c|}{$\begin{array}{c}\text { Piața Unirii } \\
\text { (ascending) }\end{array}$} \\
\hline $\begin{array}{c}\text { Direction of } \\
\text { movement }\end{array}$ & $\leftarrow$ & $\uparrow$ & $\rightarrow$ & $\leftarrow$ & $\uparrow$ & $\rightarrow$ & $\leftarrow$ & $\uparrow$ & $\rightarrow$ & $\leftarrow$ & $\uparrow$ & $\rightarrow$ \\
\hline $7: 30-7: 45$ & 64 & 43 & 71 & 88 & 278 & 35 & 174 & 90 & 135 & 37 & 283 & 155 \\
\hline $7: 45-8: 00$ & 78 & 65 & 95 & 125 & 486 & 44 & 263 & 124 & 183 & 75 & 386 & 242 \\
\hline $8: 00-8: 15$ & 41 & 38 & 65 & 55 & 249 & 28 & 139 & 81 & 74 & 58 & 229 & 129 \\
\hline $8: 15-8: 30$ & 21 & 28 & 27 & 41 & 182 & 21 & 113 & 63 & 85 & 31 & 163 & 86 \\
\hline $\begin{array}{c}\text { Number of } \\
\text { buses (\#/h) }\end{array}$ & - & - & - & 13 & 12 & - & 12 & - & 13 & - & 12 & 12 \\
\hline $\begin{array}{c}\text { Overall } \\
\text { number of }\end{array}$ & 204 & 174 & 258 & 355 & 1237 & 128 & 731 & 358 & 523 & 201 & 1103 & 654 \\
$\begin{array}{c}\text { equivalent cars } \\
(7: 30-8: 30)\end{array}$ & & & & & & & & & & & & \\
\hline
\end{tabular}


The number of equivalent vehicles indicated in the last row of Table 1 was determined using equation 1 for each particular flow on a street and in a certain direction. For example, for the traffic coming from Unirii square (descending) and heading straight ahead, the number is:

$\mathrm{N}_{2.2}=(278+486+249+182) * 1+(12 * 3.5)=1237$

The noise levels recorded in the crossroads in parallel with the video recording of the traffic are indicated in Table 3.

Table 3. Noise level determined in the crossroads for various time periods.

\begin{tabular}{|c|c|}
\hline Time period & Determined noise level $(\mathrm{dB})$ \\
\hline $7.30-7.45$ & 79.56 \\
\hline $7.46-8.00$ & 93.40 \\
\hline $8.01-08.15$ & 86.32 \\
\hline $8.16-8.30$ & 83.93 \\
\hline $8.31-8.45$ & 82.50 \\
\hline $12.00-12.15$ & 76.80 \\
\hline $12.16-12.30$ & 77.30 \\
\hline $12.31-12.45$ & 78.01 \\
\hline $17.00-17.15$ & 85.80 \\
\hline $17.16-17.30$ & 91.25 \\
\hline $17.31-17.45$ & 92.71 \\
\hline $17.46-18.00$ & 86.20 \\
\hline
\end{tabular}

As can be seen, there is a correspondence between the time of the maximal number of cars passing through the crossroads and the maximal noise level recording, which indicates that the solution for reducing the noise level in this crossroads resides with optimizing the traffic in the area as a whole.

The simulation of the traffic in the crossroads in the initial state, carried out using the software Synchro Studio 7 lead to the calculation of the crossroads usage capacity as visualized in Figure 2.

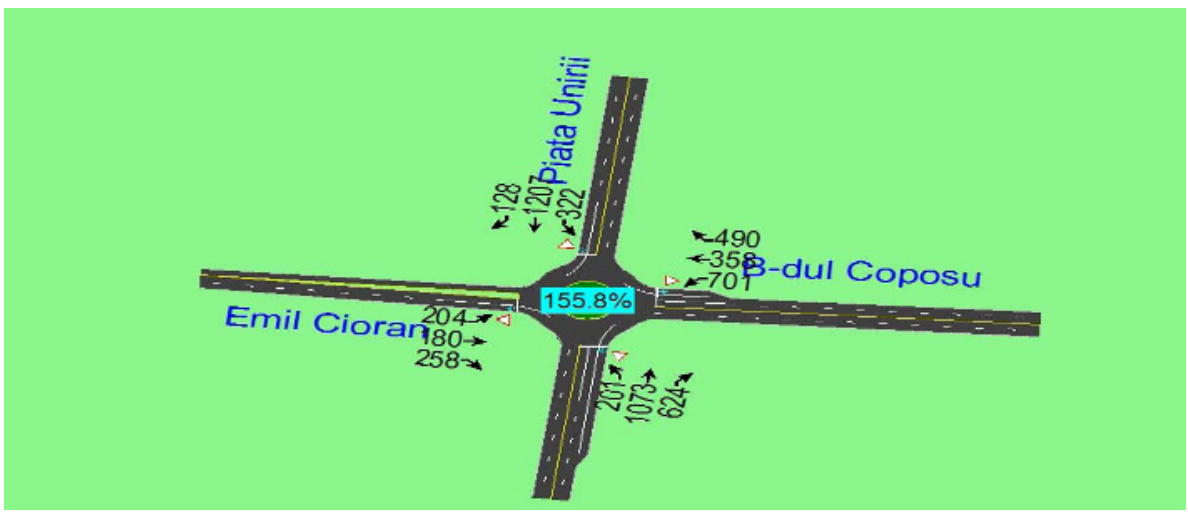

Fig. 2. Calculation of the crossroads usage capacity for the initial state of the Unirii crossroads using Synchro Studio 7.

As can be seen in Figure 2, the crossroads usage capacity exceeds $100 \%$ by far, indicating that traffic is not unfolding under normal conditions.

After applying the optimization proposal detailed in the previous paragraph, the crossroads usage capacity has decreased somewhat, as indicated in Figure 3. 


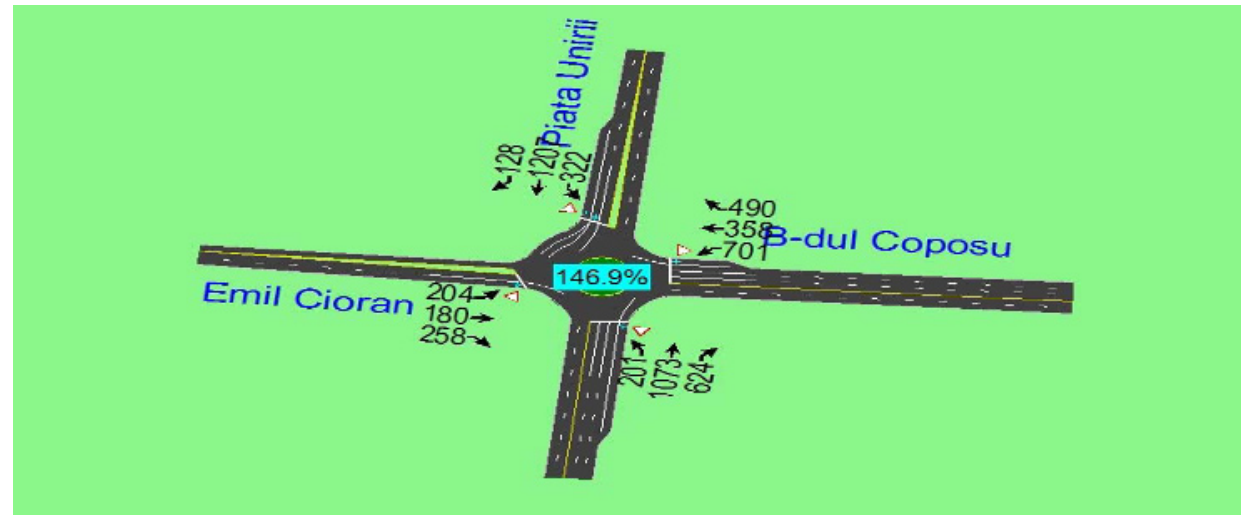

Fig. 3. Calculation of the crossroads usage capacity for the optimized Unirii crossroads, using Synchro Studio 7.

It can be thus concluded that an optimization solution of the crossroads, even if limited by the existing infrastructure, can still lead to a decrease of the noise level by about $9 \%$, i.e. by some $8-10 \mathrm{~dB}$.

\section{Conclusions}

The current paper has presented a study on the traffic conditions in a busy crossroads area in the centre of Sibiu, Romania, on the corresponding noise level and also suggested a possibility for optimizing the traffic and reducing the noise level.

The proposed optimization solution succeeded in reducing the crossroads usage capacity and the associated noise level by some $9 \%$. However, it is obvious that the resulting values are still significantly higher than those allowed by the current standards. Unfortunately, the current infrastructure conditions in the area do not allow bolder changes and thus better traffic and noise conditions.

In future, the authors intend to work together with the local authorities and with other specialists in order to find solutions for a larger reduction of the crossroads usage capacity in the area.

\section{References}

1. M. Wiering, J. van Veenen, J. Vreeken, A. Koopman, Intelligent traffic light control (Technical Report uu-cs-2004-029, Institute of Information and Computing Sciences, Utrecht University, July 2004)

2. J. Barceló, M. Delgado, G. Funes, D. García, J. Perarnau, A. Torday, SIAM News, 40, 9 (2007)

3. D. Popovici, V. Boboc, I. Găluşcă, Transport Systems and Urban Traffic (in Romanian), (Editura Societăţii Academice „Teiu Botez”, Iaşi, 2004)

4. $* * *$ SR 7348-2001, Road works. Equivalation of vehicles for determining the traffic capacity. ASRO, Bucharest, 2001

5. W. Burghout, Technical report, PREDIKT Project, (2005)

6. A. Sachelarie, E. Golgoţiu, Traffic and Road Safety (in Romanian) (Casa de Editură Venus, Iaşi, 2002). 